\title{
Iris Disorder
}

National Cancer Institute

\section{Source}

National Cancer Institute. Iris Disorder. NCI Thesaurus. Code C34737.

A non-neoplastic or neoplastic disorder that affects the iris. 